\title{
The DeVelopMent OF A HASSLE-BASED DIAGNOSTIC SCALE FOR PREDICTING BURNOUT IN CALL CENTRES
}

Authors:

Willie A. Visser ${ }^{1}$

Sebastiaan Rothmann ${ }^{1,2}$

\section{Affiliations:}

${ }^{1}$ School of Behavioural

Sciences, North-West

University, South Africa

${ }^{2}$ Department of Human

Sciences, University of

Namibia, Namibia

\section{Correspondence to:}

Sebastiaan Rothmann

e-mail:

ian@ianrothmann.com

\section{Postal address:}

PO Box 8060, Swakopmund,

Namibia 9000

Keywords:

daily hassles; job demands; family demands; exhaustion; burnout

\section{Dates:}

Received: 16 Jan. 2009

Accepted: 02 June 2009

Published: 14 Aug. 2009

How to cite this article: Visser, W., \& Rothmann, S. (2009). The development of a hassle-based diagnostic scale for predicting burnout in call centres. $S A$ Journal of Human Resource Mangement/SA Tydskrif vir Menslikehulpbronbestuur, 7(1), Art. \#181, 8 pages. DOI: 10.4102/sajhrm.v7i1.181

\section{This article is available} at:

http://www.sajhrm.co.za (c) 2009. The Authors. Licensee: OpenJournals Publishing. This work is licensed under the Creative Commons Attribution License.

\begin{abstract}
The aim of this study was to develop a brief daily hassle diagnostic questionnaire that could be used to identify daily hassles for customer service representatives within a call centre environment, and to investigate the relationship between daily hassles and burnout. A crosssectional survey was used with an accidental sample $(N=394)$ taken from a service and sales call centre. An exploratory factor analysis of the data resulted in a six-factor model of daily hassles consisting of daily demands, continuous change, co-worker hassles, demotivating work environment, transportation hassles and personal concerns. The internal consistency of one factor, namely personal concerns, was low. Exhaustion was best predicted by four categories of daily hassles, namely daily demands, continuous change, a demotivating work environment, and transportation hassles.
\end{abstract}

\section{INTRODUCTION}

A worldwide economic shift from the traditional industrial economy to the service economy has taken place with the boom in the employment of service workers (McCammon \& Griffin, 2000). One popular method that companies use for the delivery of service - specifically companies within the financial sector, travel industry and the telecommunications industry - involves the use of call centres. Call centres were mostly created as an alternative, more cost-effective service model to replace the high cost of branch infrastructure where face-to-face client interaction was the order of the day (Taylor \& Bain, 1999).

With the growth of the service economy and with call centres becoming one of the preferred ways of delivering service, the call centre industry experienced unprecedented growth, becoming one of the fastest growing employment sectors in the world. It is estimated that $2.3 \%$ of the United Kingdom population is working in call centres and that two-thirds of all customer interaction takes place through call centres. The same trends can be seen in the United States of America and Europe (Malhotra \& Mukherjee, 2004; Taylor \& Bain, 1999). Similar trends can be observed in South Africa (Briggs, 1998).

In call centres, service is rendered by customer service representatives. They are the frontline employees whose primary task is to interact with customers by means of the telephone, hence the name call centre. A customer service representative is described as someone sitting at a table in front of his/ her computer, wearing a headset, talking to customers while simultaneously entering data into the computer, if needed (Zapf, Isic, Bechtoldt \& Blau, 2003).

Customer service representatives are often referred to as boundary-spanning employees, for they represent the company to the customers - they represent '... the personality of the firm to the customer over the telephone ...' and the customers to the company (Deery, Iverson \& Walsh, 2004, p. 8). They are often placed in a difficult position when their clients want something of the company, but they cannot provide it to the customers (Singh \& Goolsby, 1994).

While nothing seems to stop the growth of call centres and the increase of employment opportunities within them, working in call centres is not always experienced as pleasant. In fact, call centres have often been referred to in derogatory terms such as 'dark satanic mills', 'electronic sweatshops' or 'assembly lines in the head' (Deery \& Kinnie, 2004; Taylor \& Bain, 1999). For example, one study conducted in German call centres found that call centre agents had poorer working conditions and experienced more psychosomatic complaints than employees in comparable but more traditional workplaces, e.g. bank and administrative clerks (Grebner et al., 2003).

Building on the idea that working in call centres is not always pleasant, it has been found that call centres are frequently seen as stressful workplaces and that working in them can foster burnout. In their review on job burnout, Cordes and Dougherty (1993) identified the nature of employee-client relationships as a critical factor contributing to burnout, specifically with regard to the frequency and intensity of client contact. Employees such as service representatives, who fulfil boundary spanning roles, have frequent and intense interpersonal contact with clients and will be more prone to the development of burnout than other employees who have less frequent and intense client contact.

The stressful nature of call centre work and its contribution to burnout has been corroborated by other research. The service job in call centres is seen as one of the ten most stressful jobs in today's economy (Malhotra \& Mukherjee, 2004). Deery et al. (2004) found that the levels of job stress among call centre staff were high, with two-thirds of the sample reporting a degree of stress. A high level of stress and emotional exhaustion was also reported for call centre staff in Australia (Deery, Iverson \& Walsh, 2002). Deery et al. (2002) found high levels of stress in call centres, with $80 \%$ of the employees requesting training in stress management. They quote an ACA research study which claims that call centre agents have a stress profile higher than that of coal miners (Wallace, Eagleson \& Waldersee, 2000). Research by Holdsworth and Cartwright (2003) has shown that customer service representatives 
found all aspects of their job more stressful than the general working population. Examining the effect of emotional labour on emotional exhaustion in call centres revealed that call centre workers experienced a moderate level of emotional exhaustion (Lewig \& Dollard, 2003). In a similar vein, Singh and Goolsby (1994) also noted that employees working in call centres are highly prone to burnout, more so than in any other work environment.

Burnout has been linked to negative organisational outcomes such as low job satisfaction, low morale, and high levels of absenteeism and turnover. On the individual level, the emotional consequences of burnout are even more serious. It leads to a decline in mental health, which is characterised by a lowering of self-esteem, increased depression, irritability, helplessness, anxiety and sleep disturbances (Maslach \& Leiter, 1997; Singh, 2000; Singh \& Goolsby, 1994).

Many different factors have been associated with the development of burnout in call centres. Some of the key factors noted by researchers in this terrain are work overload; pressure from management to maximise client throughput which is linked to contradictory demands from management; tenure; repetitive nature of the work; lack of task variety; lack of supervisor and co-worker support; lack of training to deal with job requirements; customer service representatives who perceive that customers are becoming more difficult to satisfy; tightly scripted telephone conversations; emotionally exhausting labour; continuous monitoring of performance; perceived lack of job and promotion opportunities; number of calls taken per day; pressure from management to shorten wrap-up time; role conflict; role ambiguity; and lack of job control (Bakker Demerouti \& Schaufeli, 2003; Deery et al., 2004; Frenkel, Tam Korczynski \& Shire, 1998; Holman, 2004; Singh, 2000; Singh \& Goolsby, 1994; Taylor \& Bain, 1999; Wallace et al., 2000).

\section{Daily hassles and burnout}

From the above, it is clear that there is an extensive list of factors within the work environment of call centres that can result in burnout. Burnout can be seen as a kind of a stress that develops over time in response to stressful work conditions (Cordes \& Dougherty, 1993). It develops as a result of many and everpresent role stressors, which cumulatively overwhelm the coping resources of the individual (Singh, 2000).

Conceptually, burnout consists of three separate but interrelated constructs, namely emotional exhaustion, depersonalisation, and reduced personal accomplishment. The first construct, emotional exhaustion, is thought to be the most important factor in burnout and is usually the first reaction to set in. It refers to feelings of emotional depletion and extreme tiredness in which the individual does not have the resources to cope with the emotional demands of the work (Cordes \& Dougherty, 1993; Maslach, Schaufeli \& Leiter, 2001; Schutte, Toppinen, Kalimo \& Schaufeli, 2000). Schaufeli and Enzmann (1998) identified exhaustion as a core indicator of burnout. Chronic exhaustion can lead people to distance themselves emotionally and cognitively from their work, so that they are less involved with or responsive to the needs of other people or the demands of the task (Maslach, 1998).

One of the factors often associated with burnout is daily hassles, which have not been listed as a cause of burnout in call centres. Daily hassles can be defined as minor everyday events (little things), experiences, encounters, conditions and/or thoughts that occur in daily living and are harmful to the well-being of the people that experience them - in the sense that they irritate and distress people (Lazarus, 1999; Lu, 1991; Maybery \& Graham, 2001). Daily hassles are chronic, that is, constantly recurring, role-related stressors. They are obstacles that disrupt goaldirected behaviour, since they act as a barrier between a person and his/her goals (Zohar, 1999).
Steward and Barling (1996) and Zohar (1999) aptly describe the hypothesised link to burnout. Daily hassles function as a source of stress and require the use of additional energy. The additional consumption of energy results in cognitive fatigue, lowered performance and a decrease in helping behaviour (Steward \& Barling, 1996). The disruption of goal-directed behaviour is the mechanism by which daily hassles lead to the depletion of energy. People invest energy in the achievement of their goals. Daily hassles are disruptions or obstacles that stand in the way of goal achievement. To cope with the disruption, people need to invest additional energy to find a solution through the development of action plans, problem solving and decision making. Coping consumes energy, a limited resource, which reduces the available energy for the achievement of the original goal. This process results in fatigue and negative mood, which will deteriorate even further without successful coping and energy replenishment (Steward \& Barling, 1996; Zohar, 1999).

Hassles are thus seen as 'annoying episodes' - regulation obstacles - that prevent the achievement of goals and increase the demand on personal energy, as they make daily tasks more difficult to complete. If people cannot reach their goals because of obstacles that stand in their way, they become stressed and need to invest additional energy to overcome such obstacles, which can lead to the depletion of energy resources (Grebner et al., 2003). Thus daily hassles can be regarded as an additional demand stressor (Zohar, 1999).

Daily hassles are considered harmful. Their harmful effect has been demonstrated in many research settings. Such daily hassles, and especially their accumulated effect, are associated with symptoms related to physical health, well-being, mood, illness, functioning of the immune system, job performance, absenteeism, mental health, psychological distress and stress (Barling \& Kryl, 1990; Chamberlain \& Zika, 1990; De Longis, Folkman \& Lazarus, 1988; Eckenrode, 1994; Greene \& Nowack, 1995; Lu, 1991; Steward \& Barling, 1996; Zohar, 1999).

In summary, it is evident that the call centre industry is growing, with more and more people employed in call centres. They are seen as stressful environments to work in and are conducive to the development of burnout. One of the factors that contributes to burnout is daily hassles. While they are considered to be a good predictor of burnout, they are not mentioned as a cause of burnout in call centres. The effect of daily hassles on the development of burnout in call centres has not been studied yet.

The aim of this study was to develop a daily hassle diagnostic questionnaire that can be used to identify the most common daily hassles that customer service representatives experience, and to investigate the relationship between daily hassles and burnout in call centres.

\section{Research approach}

\section{RESEARCH DESIGN}

A cross-sectional survey research design was used to accomplish the objectives set out for this research. Such a research design is appropriate for exploratory and descriptive research with the aim of developing and validating new questionnaires (Mouton, 2001).

\section{Research design Participants}

An accidental sample of call centre workers was obtained. Participants in the study were taken from a service and sales call centre situated in the Western Cape and Durban. A total of 500 questionnaires were distributed and 394 were returned, giving a response rate of $78.8 \%$. To ensure a good response rate, participants were allowed time off to complete the questionnaire during their working day. 
TABLE 1

Characteristics of participants $(N=394)$

\begin{tabular}{|c|c|c|c|}
\hline ITEM & CATEGORY & FREQUENCY & PERCENTAGE \\
\hline Call centre location & $\begin{array}{l}\text { Cape Town } \\
\text { Durban }\end{array}$ & $\begin{array}{l}208 \\
186\end{array}$ & $\begin{array}{l}52.8 \\
47.2\end{array}$ \\
\hline Type of work in CC & $\begin{array}{l}\text { Customer service } \\
\text { Sales } \\
\text { MV }\end{array}$ & $\begin{array}{r}255 \\
128 \\
11\end{array}$ & $\begin{array}{r}64.7 \\
33.4 \\
2.8\end{array}$ \\
\hline Organisational level & $\begin{array}{l}\text { Consultant } \\
\text { Supervisor } \\
\text { Leadership } \\
\text { MV }\end{array}$ & $\begin{array}{r}331 \\
32 \\
2 \\
29\end{array}$ & $\begin{array}{r}84.0 \\
8.1 \\
0.5 \\
7.4\end{array}$ \\
\hline Type of call centre & $\begin{array}{l}\text { Inbound } \\
\text { Outbound } \\
\text { Combination } \\
\text { MV }\end{array}$ & $\begin{array}{r}211 \\
120 \\
52 \\
11\end{array}$ & $\begin{array}{r}53.6 \\
30.5 \\
13.3 \\
2.8\end{array}$ \\
\hline Employment status & $\begin{array}{l}\text { Permanent } \\
\text { Temp assignment } \\
\text { MV }\end{array}$ & $\begin{array}{r}155 \\
217 \\
22\end{array}$ & $\begin{array}{r}39.3 \\
55.1 \\
5.6\end{array}$ \\
\hline Race group & $\begin{array}{l}\text { White } \\
\text { Black } \\
\text { Coloured } \\
\text { Indian } \\
\text { MV }\end{array}$ & $\begin{array}{r}8 \\
201 \\
150 \\
23 \\
12\end{array}$ & $\begin{array}{r}2.0 \\
51.0 \\
38.1 \\
5.8 \\
3.1\end{array}$ \\
\hline Gender & $\begin{array}{l}\text { Male } \\
\text { Female } \\
\text { MV }\end{array}$ & $\begin{array}{r}144 \\
243 \\
7\end{array}$ & $\begin{array}{r}36.5 \\
61.8 \\
1.8\end{array}$ \\
\hline Language & $\begin{array}{l}\text { Afrikaans } \\
\text { English } \\
\text { Xhosa } \\
\text { Zulu } \\
\text { Sotho } \\
\text { Other } \\
\text { combinations } \\
\text { MV }\end{array}$ & $\begin{array}{r}23 \\
138 \\
59 \\
84 \\
14 \\
65 \\
11\end{array}$ & $\begin{array}{r}5.8 \\
35 \\
15 \\
21.3 \\
3.6 \\
16.5 \\
2.8\end{array}$ \\
\hline Age & $\begin{array}{l}18-20 \text { years } \\
21-30 \text { years } \\
31-40 \text { years } \\
41-50 \text { years } \\
\text { MV }\end{array}$ & $\begin{array}{r}25 \\
292 \\
45 \\
13 \\
19\end{array}$ & $\begin{array}{r}6.4 \\
74.2 \\
11.4 \\
3.6 \\
4.8\end{array}$ \\
\hline Educational level & $\begin{array}{l}\text { Grade } 10,11,12 \\
\text { Technikon degree } \\
\text { University degree } \\
\text { Postgraduate } \\
\text { MV }\end{array}$ & $\begin{array}{r}217 \\
120 \\
28 \\
16 \\
13\end{array}$ & $\begin{array}{r}55.1 \\
30.5 \\
7.1 \\
4.1 \\
3.3\end{array}$ \\
\hline $\begin{array}{l}\text { Years of } \\
\text { employment }\end{array}$ & $\begin{array}{l}1-2 \text { years } \\
3-4 \text { years } \\
5 \text { years and more } \\
\text { MV }\end{array}$ & $\begin{array}{r}291 \\
32 \\
5 \\
66 \\
\end{array}$ & $\begin{array}{r}74 \\
8.2 \\
1.5 \\
16.8 \\
\end{array}$ \\
\hline
\end{tabular}

Slightly more participants were located in Cape Town (52.8\%) than in Durban $(47.2 \%)$. The majority worked in a serviceoriented call centre $(64.7 \%)$, on a consultant organisational level $(84 \%)$, taking inbound calls (53.6\%). Women constituted $61.8 \%$ of the participants. Furthermore, $51 \%$ and $38 \%$ of the participants were black and coloured respectively. A total of $55.1 \%$ of the participants was temporarily employed. Most participants $(74.2 \%)$ were between 21 and 30 years of age, while $74 \%$ of all participants had between one and two years of employment. Most had attained an educational level of grade 12 (55.1\%). English (35\%) and Zulu (21.3\%) were the most frequently used home languages (See Table 1).

\section{Measuring instruments}

Two measuring instruments were used in this study: The Call Centre Daily Hassle Scale, which was specifically developed for the purpose of this study, and the Exhaustion Subscale of the Maslach Burnout Inventory - General Survey (Maslach, Jackson \& Leiter, 1996).

The Call Centre Daily Hassle Scale (CCDHS) was developed in two phases. The first was a qualitative phase in which call centre agents were asked to identify the daily hassles that they encountered regularly, both within the call centre and in their personal lives. In the second phase, the qualitative information was used to develop the CCDHS. As part of an organisational diagnostic process, data was gathered from customer service representatives receiving client queries on the phone within a large South African financial services company. Each customer service representative was given a brief structured questionnaire
TABLE 2

Descriptive statistics for the densest daily hassles

\begin{tabular}{|c|c|c|c|}
\hline $\begin{array}{l}\text { RANK } \\
\text { ORDER }\end{array}$ & DENSEST DAILY HASSLES & MEAN & $S D$ \\
\hline 1 & $\begin{array}{l}\text { System problems (e.g. slow response times, } \\
\text { system errors and computer downtime) }\end{array}$ & 7.63 & 1.99 \\
\hline $2^{*}$ & My general financial situation & 7.30 & 2.51 \\
\hline 3 & Pressure to meet daily production target & 6.45 & 2.56 \\
\hline 4 & $\begin{array}{l}\text { Continuous changes in work procedures and } \\
\text { work environment }\end{array}$ & 6.43 & 2.74 \\
\hline 5 & Noisy co-workers - people that talk too loudly & 6.34 & 2.81 \\
\hline $6^{*}$ & Traffic jams & 6.34 & 3.01 \\
\hline 7 & $\begin{array}{l}\text { Ineffective business processes/work } \\
\text { procedures }\end{array}$ & 6.19 & 2.56 \\
\hline 8 & $\begin{array}{l}\text { Continuous changes in work processes and } \\
\text { procedures }\end{array}$ & 6.17 & 2.59 \\
\hline 9 & Time pressure & 6.15 & 2.78 \\
\hline 10 & The quality evaluation system that we use & 6.08 & 2.52 \\
\hline $11^{*}$ & $\begin{array}{l}\text { Time pressure - too many things to do }- \text { not } \\
\text { enough time to do the things that I need to do }\end{array}$ & 6.08 & 2.69 \\
\hline 12 & $\begin{array}{l}\text { Difficult customers (e.g. rude, unreasonable or } \\
\text { dissatisfied customers) }\end{array}$ & 6.07 & 2.20 \\
\hline 13 & Co-workers not doing their work properly & 5.90 & 2.66 \\
\hline 14 & High production targets - targets set too high & 5.85 & 2.74 \\
\hline 15 & Complaining co-workers & 5.82 & 2.68 \\
\hline $16^{*}$ & Transportation to and from work & 5.81 & 3.02 \\
\hline 17 & $\begin{array}{l}\text { Lack of cooperation, assistance and support } \\
\text { from other departments }\end{array}$ & 5.77 & 2.86 \\
\hline 18 & Cannot get hold of customers & 5.5 & 2.88 \\
\hline 19 & Mistakes made by colleagues & 5.50 & 2.50 \\
\hline 20 & Managerial behaviour & 5.48 & 2.80 \\
\hline 21 & Continuous interruptions & 5.46 & 2.61 \\
\hline 22 & Adhering to strict work schedule & 5.39 & 2.55 \\
\hline $23^{*}$ & $\begin{array}{l}\text { Day-to-day household responsibilities like } \\
\text { washing, preparing meals (cooking) and } \\
\text { cleaning }\end{array}$ & 5.29 & 2.79 \\
\hline 24 & Unchallenging and boring work & 5.22 & 2.74 \\
\hline 25 & Insufficient training & 5.13 & 2.73 \\
\hline 26 & Unnecessary e-mails & 5.10 & 3.09 \\
\hline 27 & Continuous changes in products & 5.09 & 2.62 \\
\hline $28^{*}$ & Unemployed close family member & 5.07 & 2.89 \\
\hline
\end{tabular}

* Refers to daily hassles in $(P)$ personal life

to complete. The questionnaire supplied a definition of daily hassles, as well as some examples of what would be regarded as daily hassles. They were then asked to think of daily hassles that they encountered regularly during the previous six months, both in the work environment and in their personal lives. The content of the returned questionnaires was analysed. Daily hassles were grouped together according to themes, based on the frequency of such hassles being mentioned. The content analysis resulted in 30 themes involving daily hassles occurring in the work environment and 13 themes involving daily hassles occurring in their personal life. The identified themes were then used to develop a measurement instrument for daily hassles in call centres. Each identified theme was phrased in a short descriptive statement covering a broad range of daily stressors that a person working in a call centre might experience.

The CCDHS consisted of 43 items, 30 of which measured daily hassles in the call centre work environment and 13 items measuring daily hassles as experienced in the personal lives of 
call centre agents. The participants were asked to indicate how frequently they had encountered the identified hassles over the previous six months, on a 5-point scale ranging from 1 ('never') to 5 ('fairly often'). Then they had to indicate how stressful they found the specific hassle on a 5-point scale ranging from 1 ('not at all stressful') to 5 ('extremely stressful'). The reasons for using this way of measuring were the following: Asking participants to focus on the shorter recall period of six months presumably enables a more reliable estimate of the frequency with which the hassles occur. The frequency and stressfulness scores were combined to provide a hassle density score. The hassle density score provides a better prediction of burnout than the frequency and/or stressfulness scores on their own (Zohar, 1997).

Exhaustion was measured by using five items from the Exhaustion Subscale of the Maslach Burnout Indicator General Survey (MBI-GS). The response format that was used ranged from 0 ('never') to 6 ('daily'). Respondents were asked to indicate how often, if ever, they experienced each of the situations described in the statements. Sample items were: 'I feel emotionally drained by my work', 'I feel used up at the end of the workday' and 'Working all day is really a strain for me.' The reliability of the scale was calculated, using the Cronbach alpha coefficient $(\alpha=0.87)$.

\section{Research procedure}

The participants gave informed consent to indicate their willingness to participate in the study by signing a return slip. The first author asked coordinators monthly to remind respondents to submit completed questionnaires. The researcher administered hard copies of the questionnaires to participants in the different organisations. The questionnaires were completed anonymously by participants and collected by the researcher after completion. All ethical guidelines in the treatment of human subjects in research were observed in all steps of the study.

\section{Statistical analysis}

All statistical analyses were carried out with SPSS version 14 (SPSS, 2007). Basic descriptive statistics (means and standard deviations) were used to determine the densest daily hassles. Various multivariate data analysis techniques were used: To determine the underlying factor structure, an exploratory factor analysis was undertaken, using the principal component method with a varimax rotation. Eigenvalues of one and higher, as well as the scree plot, were used to determine which factors to retain. This was followed with principal axis factor analysis, the results of which are reported. To determine the internal consistency of the measurement scales, Cronbach alpha coefficients were calculated for each scale.

Product-moment correlation coefficients were used to determine the relationships between the different variables and multiple regression analysis was used to determine the predictive value of daily hassles on emotional exhaustion. In terms of statistical significance, it was decided to set the value at a $99 \%$ confidence interval level ( $p \leq 0.01)$. Effect sizes (Steyn, 1999) were used in addition to statistical significance to determine the practical significance of correlation coefficients. A cut-off point of 0.30 (medium effect, Cohen, 1988) was set for the practical significance of correlation coefficients.

\section{RESULTS}

One of the outcomes of this study was to develop a short diagnostic scale of daily hassles occurring in the lives of call centre agents. To achieve this outcome, the data was analysed and screened to determine which daily hassles occurred most frequently, as well as which hassles were seen as the most stressful. These two indicators were combined to give a density score (the sum of frequency and stressfulness). Only those hassles with a density score of 5 or more out of a possible 10 were used for further analysis as they represent the more meaningful hassles (see Table 2).

According to Table 2, the top five daily hassles experienced by call centre employees in their work environment related to system problems, pressure to meet production targets, continuous changes in work procedures, noisy co-workers and ineffective business processes/work procedures. The top five hassles in their personal life related to their general financial situation, traffic jams, time pressures (having too many things to do in limited time available), transportation to and from work and day-to-day household responsibilities like washing, preparing meals and cleaning.

The 28 densest hassles were subjected to a principal components exploratory factor analysis with a varimax rotation to determine the underlying factor structure, which was followed by a principle axis factor analysis. The Kaiser-Meyer-Olkin measure of sampling adequacy was 0.87 , which indicates a sufficient sample size in relation to the number of variables $(N=394)$ to yield distinct and reliable factors (Field, 2000). Based on the Kaiser-Guttman rule of eigenvalues of one and more, as well as a visual interpretation of the scree plot, six factors were retained. The six-factor solution accounted for $39 \%$ of the variance. From the initial 28 items used in the factor analysis, 11 items were discarded on the basis of significant cross-loadings and individual $\mathrm{KMO}$ values of below 0.50 on the anti-image matrix (Field, 2000).

Factor 1, labelled 'Daily demands', consisted of three items, had an eigenvalue of 6.90 and contributed $24.64 \%$ of the variance. This factor included hassles that could be seen as demands that were made on call centre agents and included items like: 'High production targets - targets set too high', 'Pressure to meet daily production targets', and 'Time pressure'.

Factor 2 was labelled 'Continuous change' and consisted of three items. It had an eigenvalue of 7.92 and contributed $7.92 \%$ of the cumulative variance. This factor relates to the fast-changing nature of the work and products in call centres. Examples included: 'Continuous changes in the work processes and procedures' and 'Continuous changes in products'.

Factor 3 was labelled 'Co-worker hassles'. It consisted of three items, had an eigenvalue of 1.7 and contributed $6.22 \%$ of the variance. Example items included: 'Co-workers not doing their work properly', 'Mistakes made by colleagues' and 'Continuous interruptions'.

Factor 4 was described as 'Demotivating work environment' and consisted of three items. This factor had an eigenvalue of 1.34 and contributed $4.84 \%$ of the variance. Sample items included: 'Managerial behaviour', 'Lack of cooperation, assistance and support from other departments' and 'Unchallenging and boring work'. This factor was difficult to label because of the seemingly disparate items grouped together.

Factor 5 was labelled 'Transportation hassles' and consisted of two items. This factor had an eigenvalue of 1.30 and explained $4.66 \%$ of the variance. It reflects the transportation difficulties that employees experience every day. The two items that made up this factor were 'Traffic jams' and 'Transportation to and from work'.

Factor 6, labelled 'Personal concerns', consisted of three items. It had an eigenvalue of 1.16 and explained $4.14 \%$ of the variance. The factor reflected the personal concerns that people have during their working day. All of these personal concerns come from the agent's personal life and are outside of the working domain. Example items were: 'Day-to-day household responsibilities like washing, preparing meals and cleaning', 'My general financial position' and 'Unemployed close family member'. 
TABLE 3

Descriptive statistics and product-moment correlations

\begin{tabular}{|c|c|c|c|c|c|c|c|c|c|c|c|}
\hline \multicolumn{2}{|c|}{ SCALE } & ITEMS (n) & MEAN & $S D$ & $\alpha$ & 1 & 2 & 3 & 4 & 5 & 6 \\
\hline 1 & Exhaustion & 5 & 8.46 & 6.72 & 0.87 & - & - & - & - & - & - \\
\hline 2 & Daily demands & 3 & 18.45 & 6.61 & 0.75 & $0.35^{*+}$ & - & - & - & - & - \\
\hline 3 & Continuous change & 3 & 17.71 & 6.49 & 0.75 & $0.32^{*+}$ & $0.38^{*+}$ & - & - & - & - \\
\hline 4 & Co-worker hassles & 3 & 16.87 & 6.11 & 0.69 & $0.27^{*}$ & $0.28^{*}$ & $0.48^{*+}$ & - & - & - \\
\hline 5 & $\begin{array}{l}\text { Demotivating work } \\
\text { environment }\end{array}$ & 3 & 16.48 & 6.39 & 0.64 & $0.32^{* \dagger}$ & $0.22^{*}$ & $0.44^{*+}$ & $0.49^{*}+$ & - & - \\
\hline 6 & Transportation hassles & 2 & 12.15 & 5.26 & 0.68 & $0.23^{*}$ & $0.25^{*}$ & $0.19^{*}$ & $0.24^{*}$ & $0.21^{\circ}$ & - \\
\hline 7 & Personal concerns & 3 & 17.67 & 6.00 & 0.56 & - & - & - & - & - & - \\
\hline
\end{tabular}

* Correlation is significant at the 0.01 level (1-tailed)

$\dagger r>0.30$ - practically significant medium effect)

TABLE 4

Regression analysis with daily hassles as independent variables and exhaustion as dependent variable

\begin{tabular}{|c|c|c|c|c|c|c|c|c|c|c|}
\hline \multirow[t]{2}{*}{ MODEL } & & \multicolumn{2}{|c|}{$\begin{array}{l}\text { UNSTANDARDISED } \\
\text { COEFFICIENTS }\end{array}$} & \multirow{2}{*}{$\begin{array}{l}\text { STANDARDISED } \\
\text { COEFFICIENTS } \\
\text { Beta }\end{array}$} & \multirow[t]{2}{*}{$t$} & \multirow[t]{2}{*}{$p$} & \multirow[t]{2}{*}{$F$} & \multirow[t]{2}{*}{$R$} & \multirow[t]{2}{*}{$R^{2}$} & \multirow[t]{2}{*}{$\Delta \boldsymbol{R}^{2}$} \\
\hline & & B & SE & & & & & & & \\
\hline \multirow[t]{7}{*}{1} & Summary & & & & & & $20.92 *$ & 0.46 & $0.21 *$ & $0.21 *$ \\
\hline & (Constant) & -3.54 & 1.24 & & -2.87 & 0.004 & & & & \\
\hline & Daily demands & 0.24 & 0.05 & 0.23 & 4.64 & $0.000 *$ & & & & \\
\hline & Continuous change & 0.11 & 0.06 & 0.11 & 1.97 & $0.049^{*}$ & & & & \\
\hline & Co-worker hassles & 0.05 & 0.06 & 0.05 & 0.09 & 0.386 & & & & \\
\hline & Demotivating work environment & 0.19 & 0.06 & 0.18 & 3.40 & $0.001 *$ & & & & \\
\hline & Transportation hassles & 0.13 & 0.06 & 0.10 & 2.19 & $0.029 *$ & & & & \\
\hline
\end{tabular}

$* p<0.05-$ statistically significant

The six subscales of the CCDHS were subjected to a secondorder factor analysis, using the subscale totals as raw data to determine the relationships among the subscales. The principal factor analysis with a varimax rotation yielded two factors with eigenvalues of 2.50 and 1 respectively. The factors explained $59 \%$ of the variance. The first factor had to do with daily hassles in the work environment and explained $42 \%$ of the variance. The component loadings for this factor were 'Continuous change' (0.82), 'Co-worker hassles' (0.77), 'Demotivating work environment' (0.73) and 'Daily demands' (0.53). The second factor had to do with daily hassles in the personal life of the agents and explained $17 \%$ of the variance. The component loadings for this factor were 'Transportation hassles' (0.83) and ‘Personal concerns' (0.78).

\section{Descriptive statistics and correlations}

The descriptive statistics, number of items used in each scale, Cronbach alpha coefficients and correlation coefficients of the scales are displayed in Table 3.

In Table 3 it is clear that the scale reliabilities vary between 0.56 and 0.87. The Cronbach alpha coefficient for Personal concerns $(\alpha=0.56)$ was low compared to the guideline of 0.70 (Nunnally \& Bernstein, 1994). Acceptable reliability coefficients were obtained for Emotional exhaustion (0.87), Daily demands (0.75) and Continuous change (0.75). The reliability coefficients for Coworker hassles (0.69), Demotivating work environment (0.64) and Transportation hassles (0.68) can be considered acceptable if it is taken into consideration that the scales consist of only three, three and two items respectively. A reliability coefficient of 0.82 was calculated for the total daily hassle scale, which consisted of 17 items.

A statistically significant correlation was found between the full (all 17 items) Daily Hassle Scale $(r=0.44)$ and Exhaustion. This correlation can be interpreted as a medium effect (Steyn, 1999). All the subscales of the Daily Hassle Scale are significantly $(p$ $<0.01)$ related to Emotional Exhaustion. In descending order, the correlations are Daily demands $(0.35$, medium effect), Continuous change $(0.32$, medium effect), Demotivating work environment (0.32, medium effect), Co-worker hassles (0.27, small effect), and Transportation hassles (0.23, small effect). Other interesting correlations are Daily demands, which are significantly related with Continuous change $(0.38$, medium effect), whereas Continuous change is significantly correlated with Co-worker hassles (0.48, medium effect) and Demotivating work environment (0.44, medium effect). Co-worker hassles and Demotivating work environment are significantly related to each other $(0.49$, medium effect).

\section{Multiple regression analysis}

The influence of the daily hassle subscales on exhaustion was examined through multiple regression analysis. Based on the alpha values of the subscales $(\alpha>0.60)$, it was decided to include five of the subscales in the regression model. These variables were entered simultaneously into the regression model to determine the most significant predictors of exhaustion.

On the basis of the multiple regression procedure, four of the daily hassle subscales contributed significantly to the variance in emotional exhaustion (see Table 4).

The results in Table 4 show that approximately $21 \%$ of the variance in Exhaustion (as measured by the Exhaustion Subscale of the Maslach Burnout Inventory - General Survey) is predicted by four of the daily hassle subscales. All four of the subscales made a significant contribution to the regression model, as can be seen by the $t$ values: Daily demands $(t=4.64 p<0.05)$, Demotivating work environment $(t=3.40 p<0.05)$, Continuous change $(t=1.97 p<0.50)$ and Transportation hassles $(t=2.19$ $p<0.50)$. The standardised regression coefficients for each of the predictors were: Daily demands $(t=0.23)$, Demotivating work environment $(\beta=0.18)$, Continuous change $(\beta=0.11)$ and Transportation hassles $(\beta=0.10)$. Based on both the $t$ and $\beta$ values, it was concluded that Daily demands is the strongest predictor of Exhaustion, followed by Demotivating work environment, with Continuous change as the third strongest predictor, and Transportation hassles the fourth.

\section{DISCUSSION}

The purpose of this research was twofold. The first goal was to develop a short diagnostic questionnaire that could be used to measure the occurrence of the most common and stressful daily hassles in call centres. The second goal was to investigate 
whether the instrument could measure the relative influence of daily hassles on emotional exhaustion, which is seen as the most important aspect of burnout (Cordes \& Dougherty, 1993; Maslach, 2001; Schutte et al., 2000)

In qualitative interviews with customer service representatives, heavy work pressure was attributed to a lack of capacity (not enough customer service representatives to do all the work), constantly having to take calls without a break, and taking calls at a fast tempo. They attributed high levels of production targets to high target levels set by management, high quality standards that need to be met and that are enforced by quality checkers, and targets that are set on the basis of performance levels (standards) of top performers.

To achieve the first objective, a principle axis factor analysis based on the 28 densest hassles was conducted, which resulted in a factor structure of six factors. The six factors which constitute daily hassles in call centres are daily demands, continuous change, co-worker hassles, a demotivating environment, transportation hassles, and personal concerns. However, the last factor was removed from the analysis because it obtained a low alpha coefficient. The first factor, namely daily demands, refers to high levels of production targets, continuous pressure to meet targets, and time pressure in call centres. The second factor, namely continuous change, refers to changes in the work environment, work processes and procedures, and changes regarding products that the call centre agents need to sell or for which they have to provide after-sales service. The third factor, namely co-worker hassles, refers to co-workers not doing their work properly, mistakes made by colleagues, and continuous interruptions. The fourth factor, namely demotivating work environment, refers to managerial behaviour, lack of cooperation, assistance and support from other departments, and unchallenging and boring work. The fifth factor, namely transportation hassles, reflected the transportation problems that employees had in this call centre. Transportation hassles either referred to getting stuck in traffic or having difficulty in getting transport to and from work.

Daily demands were the most significant predictor of exhaustion. The contribution of this hassle to exhaustion is not surprising, as previous research has consistently found the following work demands to predict burnout: work pressure, heavy workload and time pressure, which lead individuals to feel that they cannot do all the work that they need to do in the allocated time (Cordes \& Dougherty, 1993; Deery et al., 2002; Maslach et al., 2001; Schaufeli \& Bakker, 2004; Zapf et al., 2003). High level of production targets in call centres can refer to a heavy client load with high levels of client contact and interaction, with no or little time out. Perceptions of too much work, experienced as too many demands made on the individual, can exhaust the energy levels of an individual (Maslach et al., 2001).

A demotivating work environment was found to be the second strongest predictor of exhaustion. No doubt this view could be true, but more enlightened management processes (supportive styles) have been reported in call centres, with a reduced effect on emotional exhaustion. In such cases team leaders were seen as managers who listened to and helped employees solve problems and who helped them to ease the tensions of call centre work (Deery et al., 2002). From previous research, it is known that call centre agents often see their work as boring and unchallenging; lacking in variety as far as skills are concerned and being monotonous (Holman, 2004). A significant positive relationship was found between routinisation of work - defined as a job which involves repetitive tasks - and emotional exhaustion (Deery et al., 2002).

Several researchers note the influence of managerial behaviour on burnout. Maslach and Leiter refer to it as the burden of micromanagement' in which every move of employees is managed by detailed policies (Maslach \& Leiter, 1997, p. 42).
It is well known in call centres that management espouses micromanagement techniques in which every move of the employees are controlled and evaluated. Management's focus on production and customer service also leads to a form of role conflict within employees who feel that these demands are incompatible with each other, which results in frustration and emotional distress (Deery et al., 2002).

A multiple case study of four call centres conducted by Wallace et al. (2000) supported this view in finding that the primary management priority was productivity, which was constantly monitored by IT systems producing productivity statistics. The statistics were used to 'drag the customer service representative[s] over the coals' if they did not meet their targets (Wallace et al., 2000 , p. 177). This type of management behaviour can be seen as very demotivating, as described by some customer service representatives in qualitative interviews. They saw managers and team leaders as people who did not care for their staff, who did not support them, who did not include them in any form of participative management practices, and who focused too much on statistics to manage them. The customer service representatives felt as if they were treated like machines and not like humans, or like numbers, not like people.

Continuous change was shown to be the third strongest predictor of exhaustion in the regression model. Previous research indicated that organisational change, like going through a downsizing process or merger, could be linked to the development of burnout (Maslach et al., 2001). Although these are more macro, organisation-wide changes, it would seem that small day-to-day changes in work requirements and processes are also linked to the development of exhaustion. This is not unlikely, as the assimilation of such changes requires individual effort.

Although co-worker hassles correlated significantly with exhaustion, it failed to be classed as a significant contributor to exhaustion in the regression model. Lack of cooperation, assistance and support from other departments was also seen as something that contributed to reduced motivation. In qualitative interviews, the customer service representatives spoke about the frustration resulting from the lack of cooperation between different departments within the call centre. They pointed fingers at the 'back-office' and blamed them for not 'going the extra mile' for the clients. They referred to 'accountabilities' within processes that were not clear, as well as a 'lack of ownership' within the other departments. No previous research could be found that linked this with the development of emotional exhaustion. It is difficult to determine which of the three items on this subscale contribute most to exhaustion. From the factor loadings of the items it seems that 'managerial behaviour', with the highest factor loading of 0.61 , might play a more significant role in this factor.

As far as the relationship between transportation hassles and exhaustion is concerned, the connection between commuting and the development of stress reactions has already been identified. Graig (1993) showed that commuters are routinely exposed to traffic congestion and that this is experienced as goal blocking (by the same mechanism as daily hassles). They also found that users of public transport are subject to stress occurring from crowding, delays in travelling and threats of victimisation.

In summary, a significant proportion of the variance of emotional exhaustion, as evident in the foregoing discussion, can be explained by a newly developed instrument called the Call Centre Daily Hassle Scale, which measures the presence and occurrence of daily hassles in call centres.

\section{Limitations}

This study had various limitations, specifically because of the cross-sectional design that was used (Sulsky \& Smith, 2005). 
Firstly, a cross-sectional design does not have the powerful control techniques that experimental research designs have and it often cannot control for confounding variables or alternative explanations. Secondly, this type of design does not establish causality, and it is difficult to make causal inferences about the effect of the independent variable(s) on the dependent variable. Thirdly, self-reports were used, which limit the responses of the participants to the items used in the scale and which do not capture the richness and variety of the responses that are possible (Sulsky \& Smith, 2005). Finally, the use of self-report measures is subject to response biases. Participants might have responded to questions in socially appropriate ways. Possible solutions for the problems inherent in cross-sectional studies have been suggested by Sulsky and Smith (2005). One of them is to use negative affectivity - a relatively stable personality trait as a controlling variable. A second solution is to use longitudinal research designs, which would lead to a richer understanding of the variables and their relationships.

\section{Conclusion}

With this research, an attempt was made to develop a daily hassle diagnostic scale for use in call centres. The final version of the CCDHS - a short scale - consists of 17 items. Such a short scale, which is easy and quick to complete, will fit in with the fast and unrelenting pace of a call centre, where time is always of the essence. It is a useful tool for management to use for quick diagnostic purposes - to feel the pulse of what is going on in the areas of influence. Because of the scale's brevity and easy application, it could be used on a more frequent basis and the data could form part of the balance scorecard of the call centre. The information gained from the instrument could be used to drive organisational development and change interventions by means of a cycle of measuring (getting the data), giving feedback to the participants, organising focus groups to generate solutions, implementing the solutions, and re-measuring down the line to assess the impact of changes, with regard to the occurrence of hassles as well as their impact on burnout.

The scale is in its infancy and several recommendations for further research can be made. The scale needs to be refined by eliminating weak items and items with ambiguous meanings. More qualitative research needs to be done to determine whether there are other significant hassles that have not been captured yet. It needs to be tested in different call centres to determine its test-retest reliability and its convergent validity.

\section{REFERENCES}

Bakker, A.B., Demerouti, E., \& Schaufeli, W.B. (2003). Dual processes at work in a call centre: An application of the job demands-resources model. European Journal of Work and Organizational Psychology, 12, 393-417.

Barling, J., \& Kryl, P. (1990). Moderators of the relationship between daily work stressors and mood. Work E Stress, 4 , 319-329.

Briggs, A. (1998). The 1998 South African call centre benchmarking report. Cape Town: The Merchants Group.

Chamberlain, K., \& Zika, S. (1990). The minor events approach to stress: Support for the use of daily hassles. British Journal of Psychology, 81, 469-482.

Cohen, J. (1988). Statistical power analysis for the behavioral sciences (2nd edn.). Hillsdale: Lawrence Erlbaum.

Cordes, C.L., \& Dougherty, T.W. (1993). A review and an integration of research on job burnout. Academy of Management Review, 18, 621-656.

Deery, S., Iverson, R., \& Walsh, J. (2002). Work relationships in telephone call centres: Understanding emotional exhaustion and employee withdrawal. Journal of Management Studies, 39, 471-496.

Deery, S., Iverson, R., \& Walsh, J. (2004). The effect of customer service encounters on job satisfaction and emotional exhaustion. In S. Deery \& N. Kinnie (Eds.), Call centres and human resource management: A cross-national perspective (pp. 201-221). New York: Palgrave Macmillan.
Deery, S., \& Kinnie, N. (2004). Introduction: The nature and management of call centre work. In S. Deery \& N. Kinnie (Eds.), Call centres and human resource management: A cross-national perspective (pp. 1-21). New York: Palgrave Macmillan.

De Longis, A., Folkman, S., \& Lazarus, R.S. (1988). The impact of daily stress on health and mood: Psychological and social resources as mediators. Journal of Personality and Social Psychology, 54, 485-495.

Eckenrode, J. (1984). Impact of chronic and acute stressors on daily reports of mood. Journal of Personality and Social Psychology, 46, 907-918.

Field, A. (2000). Discovering statistics using SPSS for Windows. London: SAGE.

Frenkel, S.J., Tam, M., Korczynski, M., \& Shire, K. (1998) Beyond bureaucracy? Work organization in call centres. The International Journal of Human Resource Management, 9, 957-979.

Graig, E. (1993). Stress as a consequence of the urban physical environment. In L. Goldberger \& S. Breznitz (Eds.), Handbook of stress: Theoretical and clinical aspects (pp. 316-332). New York: The Free Press.

Greene, R.L., \& Nowack, K.M. (1995). Hassles, hardiness and absenteeism: Results of a 3-year longitudinal study. Work $\mathcal{E}$ Stress, 9, 448-462.

Grebner, S., Semmer, N.K., Faso, L.L., Gut, S., Kälin, W., \& Elfering, A. (2003). Working conditions, well-being, and jobrelated attitudes among call centre agents. European Journal of Work and Organizational Psychology, 12, 341-365.

Holdsworth, L., \& Cartwright, S. (2003). Empowerment, stress and satisfaction: An exploratory study of a call centre. Leadership and Organization Development Journal, 24(3), 131140.

Holman, D. (2004). Employee well-being in call centres. In S. Deery \& N. Kinnie (Eds.), Call centres and human resource management: A cross-national perspective (pp. 223-245). New York: Palgrave Macmillan.

Lazarus, R.S. (1999). Stress and emotion: A new synthesis. New York: Springer.

Lu, L. (1991). Daily hassles and mental health: A longitudinal study. British Journal of Psychology, 82, 441-449.

Lewig, K.A., \& Dollard, M.F. (2003). Emotional dissonance, emotional exhaustion and job satisfaction in call centre workers. European Journal of Work and Organizational Psychology, 12, 366-392.

Malhotra, N., \& Mukherjee, A. (2004). The relative influence of organisational commitment and job satisfaction on service quality of customer-contact employees in banking call centres. Journal of Services Marketing, 18, 162-174.

Maslach, C. (1998). A multidimensional view of burnout. In C.L. Cooper (Ed.), Theories of organizational stress (pp. 68-85). Oxford: Oxford University Press.

Maslach, C., Jackson, S.E., \& Leiter, M.P. (1996). Maslach Burnout Inventory: Manual (3rd edn.). Palo Alto: Consulting Psychologists Press.

Maslach, C., \& Leiter, M.P. (1997). The truth about burnout: How organizations cause personal stress and what to do about it. San Francisco: Jossey-Bass.

Maslach, C., Schaufeli, W.B., \& Leiter, M.P. (2001). Job burnout. Annual Review of Psychology, 52, 397-422.

Maybery, D.J., \& Graham, D. (2001). Hassles and uplifts: Including interpersonal events. Stress and Health, 17, 91-104.

McCammon, H.J., \& Griffin, L.J. (2000). Workers and their customers and clients. Work and Occupations, 27, 278-294.

Mouton, J. (2001). How to succeed in your master's and doctoral studies. Pretoria: Van Schaik.

Nunnally, J., \& Bernstein, I.H. (1994). Psychometric theory (3rd edn.). New York: McGraw-Hill.

Schaufeli, W.B., \& Bakker, A.B. (2004). Job demands, job resources, and their relationship with burnout and engagement: A multi-sample study. Journal of Organizational Behavior, 25, 293-315. 
Schutte, N., Toppinen, S., Kalimo, R., \& Schaufeli, W.B. (2000). The factorial validity of the Maslach Burnout Inventory General Survey (MBI-GS) across occupational groups and nations. Journal of Occupational \& Organizational Psychology, $73,53-67$.

Singh, J. (2000). Performance productivity and quality of frontline employees in service organizations. Journal of Marketing Research, 64(2), 15-35.

Singh, J., \& Goolsby, J.R. (1994). Behavioral and psychological consequences of boundary spanning burnout for customer service representatives. Journal of Marketing Research, 94, $558-570$.

SPSS (2007). SPSS 14.0 for Windows. Chicago: SPSS.

Steyn, H.S. (1999). Praktiese betekenisvolheid: Die gebruik van effekgroottes. Wetenskaplike bydraes - Reeks B: Natuurwetenskappe Nr. 117. Potchefstroom: PU vir CHO.

Steward, W., \& Barling, J. (1996). Daily work stress, mood and interpersonal job performance: a mediational model. Work $\mathcal{E}$ Stress, 10, 336-351.
Sulsky, L., \& Smith, C. (2005). Work stress. Belmont: Thomson Wadsworth

Taylor, P., \& Bain, P. (1999). An assembly line in the head: Work and employee relations in the call centre. Industrial Relations Journal, 30(2), 101-117.

Wallace, C.M., Eagleson, G., \& Waldersee, R. (2000). The sacrificial HR strategy in call centres. International Journal of Service Industry Management, 11(2), 174-184.

Zapf, P.F., Isic, A., Bechtoldt, M., \& Blau, P. (2003). What is typical for call centre jobs? Job characteristics, and service interactions in different call centres. European Journal of Work and Organizational Psychology, 12, 311-340.

Zohar, D. (1997). Predicting burnout with a hassle-base measure of role demands. Journal of Organizational Behaviour, 18, 101115.

Zohar, D. (1999). When things go wrong: The effect of daily work hassles on effort, exertion and negative mood. Journal of Occupational \& Organizational Psychology, 72, 265-284. 